\title{
褐藻フクリンアミジのジテルペン類によるエゾアワビに 対する摂食阻害作用*1
}

\author{
谷口和也, 蔵多一哉, 鈴木稔, 白石一成
}

(1992 年 3 月 31 日受付)
Feeding-Deterrent Activity of Diterpenes from the Brown Alga Dilophus okamurai against the Abalone
Haliotis discus hannai

\author{
Kazuya Taniguchi,*2 Kazuya Kurata, ${ }^{* 3}$ Minoru Suzuki,*4 \\ and Kazunari Shiraishi*s
}

\begin{abstract}
Feeding-deterrent activity of the methanol extract from the brown alga Dilophus okamurai was tested on the abalone Haliotis discus hannai by the cellulose plate bioassay method. From the neutral fraction of methanol extract which showed feeding-deterrent activity, the following active compounds have been obtained: three spatane-type diterpenes, two of which have also inhibited the settlement and the metamorphosis of the abalone veliger, two secospatane-type, and two cubebane-type diterpenes. It may be suggested that $D$. okamurai chemically deters predation of marine herbivores by the production of these diterpenes. Consequently, the laminariaceous brown algae, such as Eisenia bicyclis, whose sporelings are eaten by marine herbivores, can germinate in communities of $D$. okamurai to form their own large communities in place of D. okamurai.
\end{abstract}

東北地方太平洋沿岸に执いては，潮間带下部から濑深 帯にかけてコンブ科褐藻アラメ Eisenia bicyclis (KjelIman) Setchell, 次いでフミジグサ科褐藻フクリンフミ シ Dilophus okamurai Dawson, さらにサンゴモ科サビ 亜科紅藻、無節サンダモが水滩別にそれそれれ優占群落を 形成する帯状構造が認められる。プリンフミジ群落 の消長怯，アラメ群落の年々の海沉条件纪もとずく消長 と逆の関保汇方り，フラメ群落が衰退した場合分布を扗 大し，逆にアラメ群落が拡大した場合維小する。多） だ三陸の中部抽よび北部沿岸では、コンブ科褐藻マコ ンブ Laminaria japonica Areschoug 群落が消滅する とフクリンフミジがとれに代わって優占群落を形成す る。

一方、フクリンアミジ群落中には，フラ人群落衫よび 無節サンゴモ群落と比較して，植食動物の分布が柾めて
少ないことも知られている。著者らは, フクリンアミ ジ群落中に植食動物が極めて少ない理由として、フクリ ンアミジが生産する二次代謝産物である数種のジテルペ ンによってェグフワビ Haliotis discus hannai Ino 被面 子幼生の着底, 变態が阻害されること, の行動が規制されること, 忟よびキタムラサキウ二 Strongylocentrotus nudus (A. Agassiz) の拼食行動力阻 書されるこどを明らかにした。

アラメやマコンブの上らな大型海藻は，無節サンゴモ 群落のような裸地飞近い場所火萌出寸る場合，植食動物 の過剩な摄食压に上って小型の幼体のらちに消隇し，群

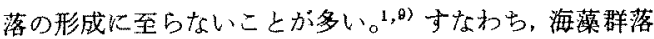
の形成に対して植食動物の摂食王はしばしば大きな阻害 的影䅗を与える。 中間㳊生育带をもち。フラ人群落の衰退域にも速やかに

*1 BCP 92-IV-D-1.

*2 東北区水陏破究所 (Tohoku National Fisheries Research Institute, Shinhama, Shiogama, Miyagi 985, Japan).

*3 画馆工業高等曹門学校 (Department of Industrial Chemistry, Hakodate Technical College, Hakodate, Hokkaido 042, Japan).

*击北海道大学理学部 (Department of Chemistry, Facuity of Science, Hokkaido University, Sapporo, Hokkaido 060, Japan).

*5 宾城県気仙沼水産試煥場 (Miyagi Prefectural Kesennuma Fisheries Experimental Station, Kesennuma, Miyagi 988-02, Japan). 


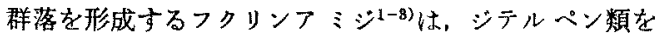

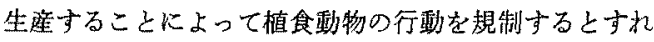
ば、フラメ群落の衰退域に拊ける再形成に対しても何等 かの影響を及ばしていると考学られる。そこで、フクり ンフミジの植食動物に対する行動規制要因を上り辣細に 明らかにするため，フクリンフミシからメタノール抽出

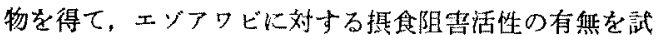
験した。その結果，フクリンアミジはキタムシサキウ二 に対するのと同様にエゾフワビに対しても強い掑食阻需 活珄をむら，掑食阻害活性物質として合計 7 種のジテル ペンを明らかにできた。これらの知見にもとつきフフ リンアミジ群落とアラメ群落との分布をめぐる関係につ いて考察を加えた。

\section{実 験 方 法}

フタリンアミシは岩手県金石市沿岸で 1991 年 6 月K 採集し，日陰で乾燥した。採集地のフクリンフミシ群落 は、マコンブ群落の衰退後に形成されたるのである。乾 燥フクリンアミジをメタノールで 1 週間浸清抽出後, 抽 出液を減王濃篗した。得られた抽出物をエーテルと水で 分配し, エーテル可溶と水可溶画分を得た。エーテル可 溶部を $5 \%$ 水酸化カリウム水溶液で抽出後, $1 \mathrm{M}$ 塩酸で 酸性にし、エーテル抽出して酸性部 (A) を得た。エーテ 儿可溶部から酸性部を抽出した残りのものには喤基性部 がほとんとななためこれを中性部 (N) とした。一方， 水可溶部を, 活性岸力ラムに吸着後, 水, メタノ一ル, およびメタノール/フンモ $=$ ア/水 $(8: 1: 1)$ で逐次溶出 ᄂ, 水溶性活性炭通過部 (WP), 水溶性入夕, 一ル溶出 部(WM), 末よび水溶性メタノール/アンモニフ溶出部 (WMA) とした。乾燥藻体 $1 \mathrm{~kg}$ 当りの, これら画分収量 をTable 1 に示した。

生物試験は、フクリンフミジのキタムラサキウニに対 する搷食阻害活性, ${ }^{8,17)}$ アミジグ业科褐藻エジヤ八ズ Dictyopteris divaricata (Okamura) Okamura $キ タ 厶$ ラサキウニ,エソフワビ,クボガイ Chlorostoma lischkei (Tapparone-Caneferi) 扎よびバティラ Omphalius pfeifferi (Philippi) に対する提食阻害活性，18,19) 特よびュン ブ科褐藻数種のエン゙フロビに対する摄食阻害活性 ${ }^{20-22)}$

Table 1. Yields of fractions obtained from the methanol extract of Dilophus okamurai ( $g / k g$ dry weight)

\begin{tabular}{ccccc}
$\mathrm{N}$ & $\mathrm{A}$ & WP & WM & WMA \\
\hline 10.3 & 6.7 & 43.7 & 0.2 & 0.5 \\
\hline
\end{tabular}

$N$, neutral part; A, acidic part; WP, fraction eluted with water from activated charcoal column; WM, fraction eluted with methanol from charcoal column; WMA, fraction eluted with methanol/ammonia from charcoal column.
の桧定に用いた方法と同様である。亦ず，直径 $20 \mathrm{~cm}$ のせルロースアルミシート (DC-Alfolien Cellulose, Merck 社製) の周縁部心直径 $2 \mathrm{~cm}$ の円を等間附で 16 区画描き，交互に対照区之試験区を配した。対照区には フワビ類の提食刺激物筫であるホスファチシルコリン

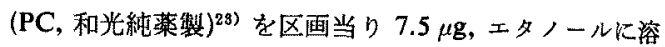
かして吸着させ、試験区には PC7.5 $\mu \mathrm{g}$ と抽出画分 75 $\mu \mathrm{g}$ を混合して吸着させた。この試験板を $20^{\circ} \mathrm{C}$ の恒温 室内で水温を調節した滹過海水を蛼たした塩化ビニール 製の円简型水槽 (值径 $30 \mathrm{~cm}$, 高さ $14 \mathrm{~cm}$ ) に沈めた。 一方, 款長 $2.5-3.0 \mathrm{~cm}$ のエゾアワピを試験開始 1 日前 から水温 $20^{\circ} \mathrm{C}$ の条件で紿食させ，各水槽に 5 個体入れ て暗期 15 時間で試験した。試験は画分当り 12 回繰り 返した。取り上げた試験板上の対照区と試験区に残され た食及跡数を湘定し, 次式の摄食選択性指数を求めた。

$$
\text { 提食退択性指数 } \quad E_{i}=\frac{P_{i}-p_{i}}{P_{i}+p_{i}}
$$

ここで， $P_{t}$ は対照区の食み跡数， $p_{i}$ は試験区の食及跡 数を示す。李た， $t$ 検定によって対照区と試験区に対す る選択の有意美を求めた。

エゾフワビに対して提食阻害活性をるつ物質の分踓精 整は，生物試験により強い活性をるつと判定された国分 について、フルミナ (Merck 社製, Aluminium oxide 90, activity II-III) カラムクロマトグラフィー, 高速液体 クロマトグラフィー (HPLC), 扰よび分取薄層クロマト グラフィー(PLC, Merck 社製、 Kieselgel $\left.60 \mathrm{~F}_{2 \mathrm{~b}}\right)$ によ って行った。HPLCは逆相系 (日本分光 Megapak SIL$\mathrm{C}_{18}$, 溶媒：メタノール/水) 扎よび順相系 (Megapak SIL-CN, 溶煤：へキ+ン/イソプロピルアルコール)で 行った。

\section{結果}

フクリンアミジの第 1 次画分から第 3 次画分までの 生物試験結果を Fig. 1 K, また, 第 2 次画分以降の物 質の分㒕精製過程を Fig. 2 に示した。第 1 次画分では， $\mathrm{N}$ 部に明らかな掑食阻害活性 $(p<0.05)$ が琶められた が，他の 4 画分には全く認められなかった。そこで， N 部をアルミナカラムクロマトグラフィーにより分画し て、N-1-6 部の第 2 次画分を得た。第 2 次画分ではN3 部が罗も強い摄食阻害活性 $(p<0.01)$ を示し, N-1 部 にも活性 $(p<0.05)$ が認められた。

明らかに摄食阻害活性が認められた $\mathrm{N}-1$ 部と N-3 部。 お゙よび $\boldsymbol{t}$ 榆定の結果では活珄を認めることはできなか。 たが，提食選択性指数が比校的高かった N-2 部との 3 画分についてさらに分画を行った。N-1 部は，PLC (溶 媒：ベンぜン）で分離し，N-1-1〜N-1-3 部を得た。N-2 部上 N-3 部は, 逆相系の HPLC (溶媒: メタノール 


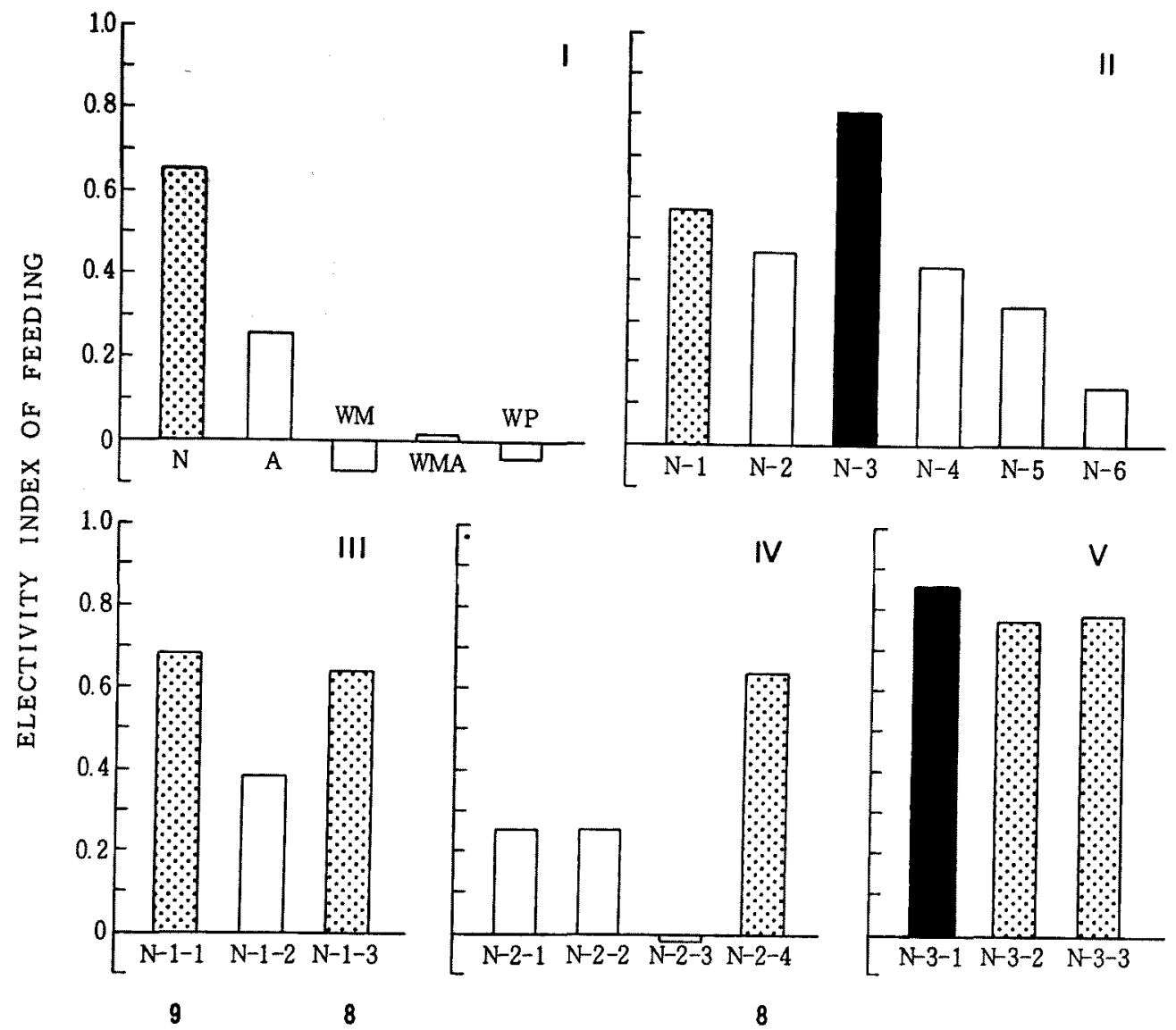

Fig. 1. Feeding-deterrent activity of the first (I), second (II), and third fractions (III, IV, and V) obtained from Dilophus okamurai against the abalone Haliotis discus hannai. N, neutral part; A, acidic part; WM, fraction eluted with methanol from activated charcoal column; WMA, fraction eluted with methanol/ammonia from charcoal column; WP, fraction eluted with water from charcoal column. The shaded and dotted bars indicate fractions which have a significant effect of $p<0.01$ and $p<0.05$ on feeding-deterrent by $t$-test.

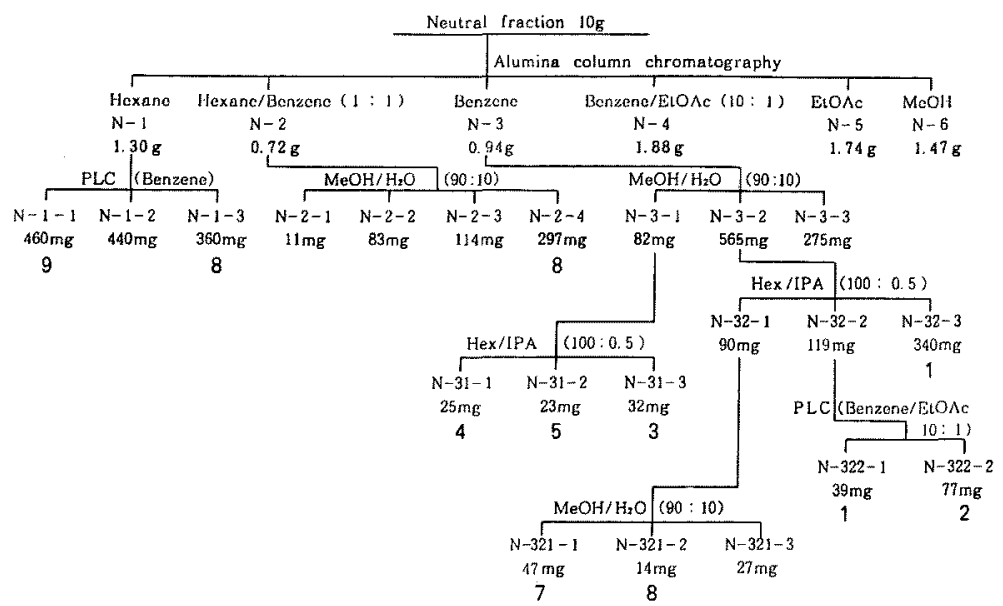

Fig. 2. Purification procedures of neutral fraction from Dilophus okamurai. 


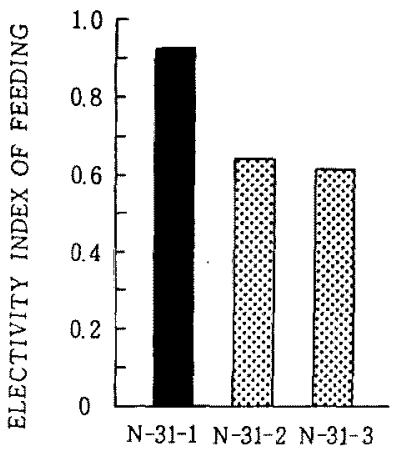

4

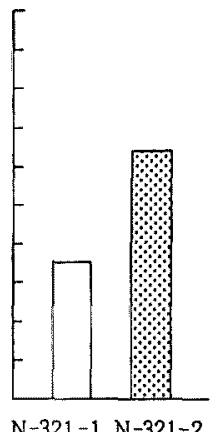

78

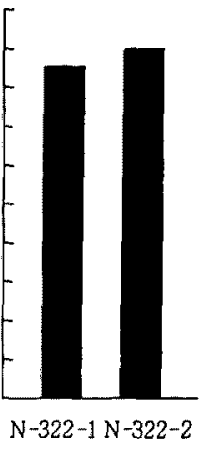

12

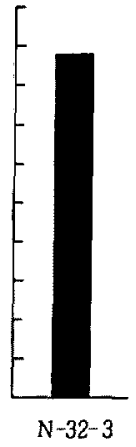

Fig. 3. Feeding-deterrent activity of 8 fractions obtained by HPLC of the third (N-3-1 and N-3-2) and fourth fractions (N-32-1 and N-32-2) against the abalone Haliotis discus hannai. The shaded and dotted bars indicate fractions which have a significant effect of $p<0.01$ and $p<0.05$ on feeding-deterrent by $t$-test.

水，90:10)で分離し，それぞれ N-2-1〜N-2-4 部および N-3-1 N-3-3 部の第 3 次画分を得た。 $\mathrm{N}$-1 部から得ら れた 3 画分においては $\mathrm{N}-1-1$ 部と $\mathrm{N}-1-3$ 部 $(p<0.05)$ に、N-2 部から得られた 4 画分においては N-2-4 部 $(p<0.05)$ に，それぞれ阻害活性が钩められた。また，第 2 次画分で最も強い阻害活性を示した N-3 部から得ら れた 3 画分においてはいずれる阻書活性が明らかに認 められ, 特に N-3-1 部の阻害活性 $(p<0.01)$ が最手強か った。

第 3 次画分で最る強い阻害活性が裙められた N-3-1 部について，順相系の HPLC (溶媒：へキサン/インプ ロピルアルコール, 100:0.5) によって分画し, N-31-1 $\mathrm{N}-31-3$ 部を得，また， N-3-2 部か、 $5 \mathrm{~N}-32-1 \sim \mathrm{N}-32-3$ 部 を得た。さらに, 逆相系の HPLC (溶媒：メタノール) 水, 90:10)によって、N-32-1 部加ら N-321-1 N-321-3 部および N-32-2 部から PLC（溶媒：ペンゼン/眽酸 エチル，10:1) によって N-322-1 部と N-322-2 部に分 画した。これらの画分のらち，N-321-3 部を除いて第 4 次扎上び第 5 次画分の生物試鈋の結果 Fig. 3 K示し た。なお，N-3-3 部について子多数の物質が含まれてい たため以後の分離は行わなかった。 N-31-1〜N-31-3 部 においてはすべてに明らかな阻豐活性少認められ，中で

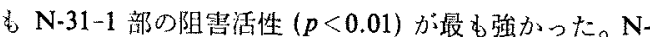
3-2 部からの画分では, N-321-2 部に强い阻害活性 $(p<$ $0.05)$ が諰められ，また，N-322-1 部と N-322-2 部に拉 いてはともに極めて強い阻害活性 $(p<0.01)$ が, さ5K,

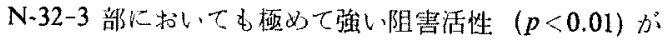
碗的ら九た。

純䊉に単離された拱食阻害活性物質の棈造式を Fig. 4 に示した。極めて强い阻害活性を示した N-322-1 部と
N-32-3 部は同一物ですり，スパタン型ジテルペンの 1 であった。また、N-322-2 部は 1 の晎性体の 2 であっ た。活性物質 1，2 はともにエソフワビ被面子幼生の着 底, 変態阻害物質 ${ }^{5,8)}$ として単離されている。N-31-3 部 は、スパタン型ジテルペンの 3 であった。

N-3 部において最も強い阻害活性を示した N-31-1 部 はセュスパタン型ジテルペンの 4 であり，N-31-2 部む セコスパタン型の 5 であった。しかし，既報のセコスパ

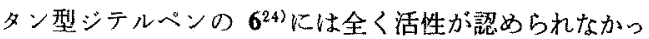
tio

N-321-1 部はキタムラサキウニに対して最毛強い䀧

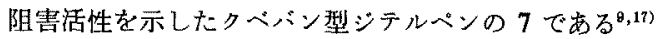
が、ェゾアワビには㤝とんど阻害活性を示さなかった。 しかし，阻害活性を示した N-1-3 部，N-2-4 部，および N-321-2 部は 7 のメチルエーテル体の 8 であった。

活性物質 8 は,フタリンアミジからメタノールで抽出 した際に生成した artifact ではないかと考えられた。こ のため，7をぬタノールに溶解し，微量の酢酸を触媒上 して室温で 2.5 時間反応させて artifact が否かの確認を 行ったところ，70\% の取率で 8 が得られた。またフ クリンフミジをてトンで抽出し、タノール抽出の務 合と同様の方法で分嵟精製したところ 7 のかが得られ。 8 は全く得られなかった。以上のことから8は7の artifact であると結諭した。

此較的强い阻害活性を示したクベバン型ジテルペン9 は，然色油状物質であり，各種スペクトルデータから9 式と決定した。その詳細については別に報告する。

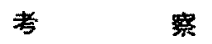

フクリンフミジのメタノール抽出物に対するエゾアワ 


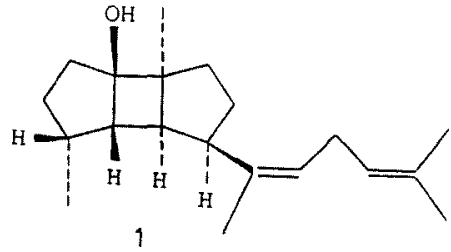

1<smiles>CC(C)=CCC=C(C)[C@H]1C[C@@H](O)C2(I)[C@H]1[C@]1(O)CC[C@H](I)[C@@]21C(=O)O</smiles>

3

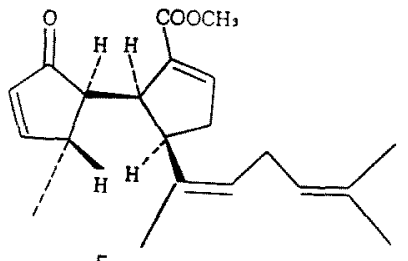

5

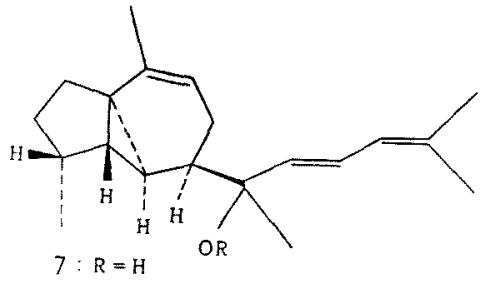

$8: \mathrm{R}=\mathrm{CH}_{3}$
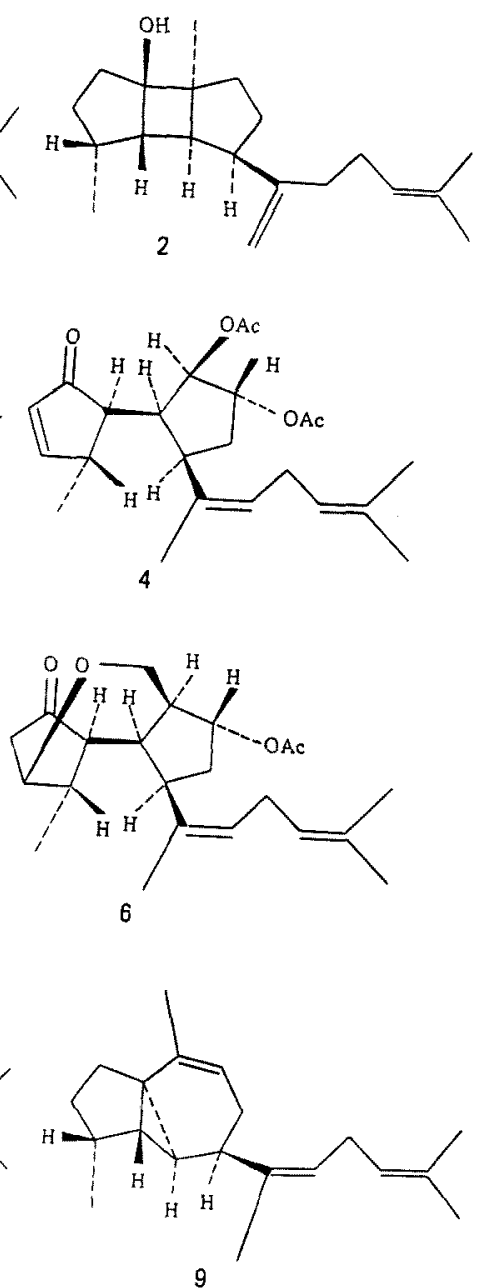

Fig. 4. Structures of diterpenes obtained from Dilophus okamurai.

ビの摃食選択性試験の結果，中性部 (N) に強い摄食阻書 活性が認められ(Fig，1)，生物試験と分離精製を繰り返 すことによって (Figs. 1-3), 掑食阻害活性物質は, エサ アワビ被面子幼生の着底, 変態の阻害活性物質を含む 3 種のスパタン型シテルペン $(1,2,3), 2$ 種のセコスパタ ソ型シテルベン $(4,5)$, および 2 種のクベヘン型ジル ベン (8,9) であること 5,0,8,8,16,17)が明らかになった (Fig. 4)。エソアワビに忌避行動を起こさせたのはこれらのジ テルペンを最も多く含む第 2 次画分 N-3 部であったこ どから，忌避行動を起こさせる要因はこれらのシテル ヘンの提食阻害活性によるとみなされよう。また，天然 物であるクベハン型ジテルペンの7には阻赛活性が認 められないのに対し，そのメチルェーテル体の 8 K活性
が范ることは，今後，檴造一活性相関の面から提食阻害 発現機棈を解明する必要がある。

以上の結果から，フクリンアミシ群落中に植食動物が 少ないといら事実は，フクリンアミジが二次代謝産物と して多数のジテルペンを生産して植食動物动生の着底, 変態阻害作用 ${ }^{b, a, 8)}$ と摂食阻害作用を発現させて植食動物 の行動を制御することによってもたらされると結論でき る。

フクリンフミジ群落は，通常アラメ群落の下限に接し て形成されて扣り、冬〜春李儿水温が低い寒命な年には， アラメ拈よびアラメと同じンンブ科のワカメUndaria pinnatifida (Harvey) Suringar およびマコンブがその群 落中に多数萌出することによって群落上層が形成される 


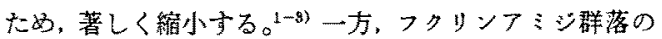
下限以㳭にみられる無節サンゴモ择落中に人為的に作出 したアラメやマュンブの幼胞子体を移植すると，そこに

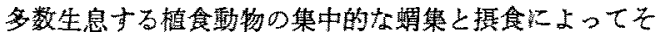
れらの幼胞子体は短期間の5ちに消减する。 の知見は，アラメなどコンブ科褐藻の萌出にとって，フ クリンフミジ群落の存在は何等影響を及ぼするのではな

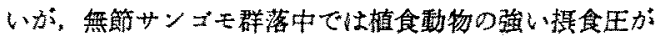
極めて阻書的に作用することを示している。以上のこと から、フクリンアミシが生産するシテルペン類は，植食

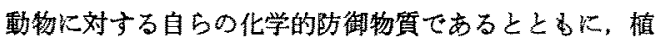
食動物を排除することによっててラか等コンブ科襡落群 落の形成棨件をなしていると考えられる。

\section{辞}

生物試験の実施に当たり，陚駼材料を提供していただ

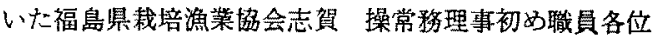

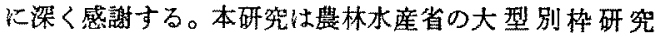
「パオコスモス語画」の一環として行われた。記して 関係各位以謝意を表与。

\section{文献}

1) K. Taniguchi: Marine afforestation of Etsenia bicyclis (Laminariaceae; Phaeophyta), NOAA Technical Report NMFS, 102, 47-57 (1991).

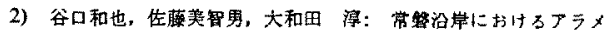

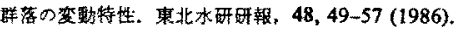

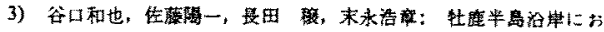

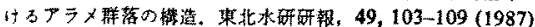

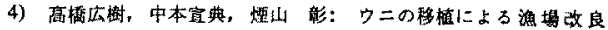

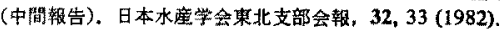

5) K. Kurata, M. Suzuki, K. Shiraishi, and K. Taniguchi: Spatane-type diterpenes with biological activity from the brown alga Dilophus okamurai. Phytochemistry, 27, 1321-1324 (1988).

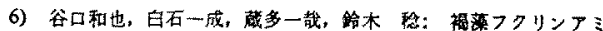
ジのタタノール抽出物に合まれるエソアワビ被面子幼生の箱掋。

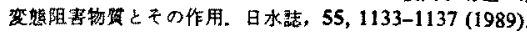

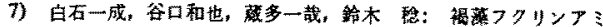

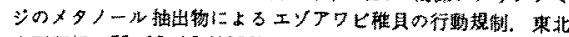
水研研報, 52,13-15 (1990).

8) K. Kurata, K. Taniguchi, K. Shiraishi, and M. Suzuki: Feeding-deterrent diterpenes from the brown alga Dilophus okamura. Phytochemistry, 29, 3453-3455 (1990).
9) H. Kito, S. Kikuchi, and N. Uki: Seaweed as nutrition for seabsd marine life technology for artificial marine forests. in "International Symposium on Coastal Pacific Marine Life" (ed. by C. J. Flora), Western Washington Univ., Bellingham, 1979, pp. 55-66.

10) G.R. Foster: The ecology of Echinus esculentus L. Quantitative distribution and rate of feeding. J. Mar. Biol. Ass. U. K., 38, 361-367 (1959).

11) D. L. Leighton: Grazing activities of benthic invertebrates in kelp beds. Beikeft zur Nova Hedwigia, 32, $421-453$ (1971).

12) J. H. Himmelman and D. H. Steele: Foods and predators of the green sea urchin Strangylocentrotus draebachiensis in Newfondland waters. Mar. Biol., 9, 315322 (1971).

13) K. H. Mann and P. A. Breen: The relation between lobster abundance, sea urchin and kelp beds. I. Fish. Res. Bd. Canada., 29, 603-609 (1972).

14) P. A. Breen and K. H. Mann: Changing lobster abundance and the destruction of kelp beds by sea urchin. Mar. Biol., 34, 137-142 (1976).

15) P. A. Breen and K. H. Mann: Destructive grazing of kelp by sea urchin in eastern Canada. I. Fish. Res. Bd. Canada, 33, 1278-1283 (1976).

16) C. Lang and K. H. Mann: Changes in sea urchin populations after the destruction of kelp beds. Mar. Biol., 36 321-326 (1976).

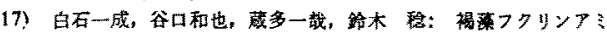

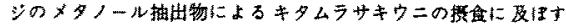

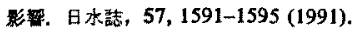

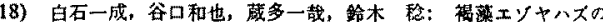
メタノール抽甠物によるキタム゙サキウニとエソアワビに対す 万拱食阻害作用。冰誌，57, 1945-1948 (1991)。

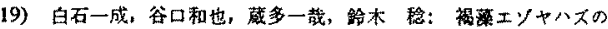

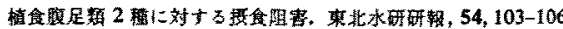
(1992).

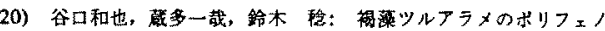

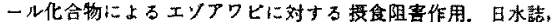
57, 2065-2071 (1991).

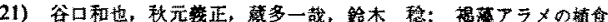

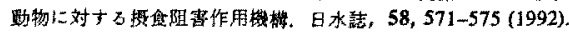

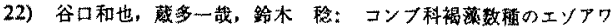

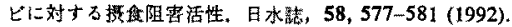

23) K. Sakata, T. Ito, and K. Ina: A new bioassay method for phagostimulants for a young abalone Haliotis disus Reeve. Agric. Biol, Chem., 48, 425-429 (1985).

24) K. Kurata, K. Taniguchi, K. Shiraishi, and M. Suzuki Structure of secospatane-type diterpenes with feedingdeterrent activity from the brown alga Dilophus okamurai. Tetrahedron Lett., 30, 1567-1570 (1989).

25) K. Kurata, K. Shiraishi, T. Takato, K. Taniguchi, and M. Suzuki: A new feeding-deterrent diterpenoid from the brown alga Dilopus okamurai Dawson. Chem. Lett., 1629-1632 (1988). 